\title{
"The effect of some technical proprioceptive neuromuscular facilities (PNF) on some physiological variables in swimming for the triathlon player"
}

\section{Introduction and research problem:}

Swimming sport occupies a prominent place among all other sports practiced by man because of its positives on the health, physical, psychological and social aspects and in order to improve its efficiency and capabilities, it is part of some other modern Olympic sports, which (modern pentathlon and triathlon), and swimming is one of the races that represent Sports triathlon, and starts the race, and free swimming is the most used in the triathlon because of its speed in performance.

The triathlon is one sport that includes three races, namely swimming, bicycles and running, in the order presented, and these competitions take place one after the other in an uninterrupted sequence, and the player must find the right balance in his energy between the three competitions.

The technique of neuromuscular facilities was also adopted to the diversity between the two types of mobile and fixed muscle contractions, which allows the muscle tissue to adapt to the nature of any muscle work performed by the player, and this method of muscle contraction depends on increasing the muscle strength that enables the player to move positively throughout the full range of the joint, Where "Kathy" stressed that stretching and strength exercises must be performed in a balanced manner, and that muscle stretching exercises work to increase flexibility and that this is a great benefit in increasing the amount of strength, by applying the method of neuromuscular facilities and obtaining a high degree of balance of strength around the Season. (9: 207)

Swimming training aims to raise the level of swimmer and record new times' and the success of the trainer in achieving this means the success of the physiological adaptation process, and until this is achieved, swimming swings between two important processes, one of which is fatigue and the other is hospitalization and elimination of fatigue, fatigue is a necessity that must occur in order for the body to overcome and succeed In this, the level of performance develops, and fatigue is a temporary decline in the ability to continue to perform work, while hospitalization is the return of the body's systems to the state they were in before the performance and to a state of pre- 


\section{performance sometimes. (2: 163).}

Triathlon is considered one of the most difficult competitions in the world, as it requires the rider to master the three sports at the same level, as it requires high physical fitness because he performs these sports in succession, without any interruption, and the rider begins to swim a distance, then he wears clothes and bicycle shoes, to cut The specified distance is by bike, then he changes his shoes again to start running, and this is all done in a row without the rider taking any rest, and the time for switching and wearing the clothes for each game is calculated within the time of the race, and therefore it is obligatory for the rider to perform it faster. Time is possible. (12: 71) (8)

When continuing to perform a physical effort, the player is exposed to what is known as the phenomenon of fatigue, whose features become clear in the form of a decrease in the level of work efficiency. It is called (central fatigue), this fatigue results from a decrease in the efficiency of the work of the nerve centers, which leads to the appearance of fatigue. As for others, the second direction of fatigue lies within the working muscle itself as the combustion products accumulate during physical work (5: 90).

"Michael" notes that the methods of neuromuscular facilities for sensory receptors at the present time are more common and used in the field of sports training, where many qualified trainers and specialists in physical fitness are using a method that supports and increases the speed of neuromuscular muscular mechanisms through the subjective excitement in which the nature of this Receptors Despite the fact that nerve facilities have more than one formations in performance, they are based on an important principle which is: "People possess an unexploited part of energy even those who are exempt"

$(10-180)$.

Through the researcher's experience of being a previous player for the triathlon as she has achieved many tournaments from 2010 to 2019 and being a current coach and approved by the International Federation and the Egyptian Federation of Triathlon, the researcher noted the low level of performance of most players in the age group from 12 to 16 years in official tournaments The researcher attributed this to skillful and physiological reasons, which is reflected negatively on the level and performance of the players.

\section{Aim for research}

The research aims to design a program using some methods of neuromuscular facilitation for sensory receptors to identify: -

- Physiological variables represented in (the level of lactic acid in the blood after the effort - the maximum oxygen consumption).

\section{Research hypotheses}

- There are statistically significant differences between the pre and post measurements in favor of the post measurement in the physiological variables represented in (the level of lactic acid in the blood after the effort - the maximum oxygen consumption). 


\section{Search terms}

*Proprioceptive Neuromuscular Facilitation (PNF)

It is the control of neuromuscular techniques by stimulating sensory receptors. (13:18)

\section{* Triathlon}

It is one competition that includes three races, namely swimming, biking and running in the order presented, and is conducted in uninterrupted sequence (procedural definition).

\section{*Fatigue Fatigue}

The process of reversing the functional ability to perform as a result of increasing its requirements at a time when the efficiency of the player to continue to exert effort (6: 47) decreases.

\section{* Lactic Acid}

The final image of anaerobic glucose representation in the body (5: 164).

\section{*Blood pressure}

It is the pressure that occurs by the blood on the walls of the blood vessels and it often indicates arterial blood pressure (3: 126).

\section{* The maximum oxygen consumption is vo2 max}

It is the amount of oxygen that a person consumes in one minute of training time (5: 329)

\section{Search procedures}

\section{Research Methodology}

The researcher used the experimental method for one group (tribal measurement - dimensional measurement) due to its relevance to the nature and objectives of the research.

\section{research community}

The research community included male and female triathlon at the Badr Sports Club and registered with the Egyptian Triathlon Federation for the 20182019 sports season.

\section{The research sample}

The researcher chose the research sample in the deliberate manner of the triathlon players in the Badr Sports Club, and their number was (20) players and their age ranges between (12-16) years, where the basic sample size (11) player and player and the number (6) players were The survey application applied to them and excluded (3) players for noncompliance, and table (13) shows the numerical distribution of the sample in question. 
Table (1)

The numerical distribution of the sample in question

\begin{tabular}{c|c}
\hline \hline the sample & Numerical distribution \\
\hline \hline Exploratory & 6 \\
\hline the basic & 11 \\
\hline Total & 17 \\
\hline \hline
\end{tabular}

* Statistical characterization and parity of the sample population in variables

The researcher made sure of the statistical description of the members of the research sample according to the variables under discussion. Table (2) indicates the homogeneity of the members of the research sample in two variables (age length - weight - training age.

Table (2)

Statistical characterization and parity of the sample population in variables(Age - Height - Weight - Training Age)

$(\mathrm{N}=11)$

\begin{tabular}{|c|c|c|c|c|c|c|c|c|}
\hline \multirow{2}{*}{ Variables } & \multirow{2}{*}{$\begin{array}{c}\text { measruing } \\
\text { unit }\end{array}$} & \multirow{2}{*}{$\bar{X}$} & \multirow[b]{2}{*}{$S$} & \multirow[b]{2}{*}{$\propto_{3}$} & \multicolumn{2}{|c|}{ Randomization } & \multicolumn{2}{|l|}{ Normality } \\
\hline & & & & & $\begin{array}{c}\text { P- } \\
\text { (value) }\end{array}$ & $\mathbf{Z}$ & P- (value) & $\mathbf{Z}$ \\
\hline Age & Year & 13.64 & 1.12 & 0.16 & 0.90 & $0.57^{*}$ & 0.90 & $0.57 *$ \\
\hline Length & $\mathrm{Cm}$ & 159.91 & 4.61 & 0.98 & 0.66 & $0.73^{*}$ & 0.66 & $0.73^{*}$ \\
\hline $\begin{array}{c}\text { the } \\
\text { weight }\end{array}$ & Kg & 52.00 & 5.97 & 1.60 & 0.41 & $0.89 *$ & 0.41 & $0.89 *$ \\
\hline $\begin{array}{l}\text { Training } \\
\text { age }\end{array}$ & Year & 2.55 & 0.52 & $\begin{array}{c}- \\
0.21\end{array}$ & 0.13 & $1.17 *$ & 0.13 & $1.17^{*}$ \\
\hline
\end{tabular}

* Indication at the value of $(\mathrm{p})<(0.05)$

Table (2) shows the arithmetic mean, the standard deviation and the torsional coefficient of the research sample in the variables (age - length - weight - training age), and the data indicate that the torsional coefficient values for the research sample are limited to $(+3)$, which indicates that the sample data does not have positive twisting Or negative, as well as the presence of statistically significant differences in the values of random and natural tests, which indicates their normal and random distribution, which confirms the equivalence of the sample members. 
Table (3)

Statistical characterization and parity of the sample population in the physiological variable (lactic acid In the blood after exertion - the maximum oxygen consumption)

$(\mathrm{N}=11)$

\begin{tabular}{c|c|c|c|c|c|c|c|c}
\hline \hline Variables & $\begin{array}{c}\text { measruing } \\
\text { unit }\end{array}$ & $\bar{X}$ & $\boldsymbol{S}$ & $\propto_{3}$ & $\begin{array}{c}\text { Randomizatior } \\
\text { (value }\end{array}$ & $\mathbf{Z}$ & $\begin{array}{c}\text { Normality } \\
\text { (value }\end{array}$ & $\mathrm{Z}$ \\
\hline \hline Lactic acid & $\begin{array}{c}\text { Micromol } \\
\text { / L }\end{array}$ & 1.12 & 0.18 & -0.05 & 0.98 & $\mathbf{0 . 0 3 *}$ & 0.92 & $\mathbf{0 . 5 5 *}$ \\
\hline $\begin{array}{c}\text { Maximum } \\
\text { oxygen } \\
\text { consumption }\end{array}$ & meter & 1522.73 & 348.83 & -0.36 & 0.96 & $\mathbf{0 . 5 0 *}$ & 0.96 & $\mathbf{0 . 5 0 *}$ \\
\hline \hline
\end{tabular}

$*$ Indication at the value of $(\mathrm{p})<(0.05)$

Table (3) shows the arithmetic mean, the standard deviation and the torsional coefficient of the research sample in the physiological variable (lactic acid in the blood after the effort - the maximum oxygen consumption), and the data indicate that the torsional coefficient values of the research sample are between (+3), which indicates that the sample data There are no positive or negative sprains in it, as well as the presence of statistically significant differences in the values of random and natural tests, which indicates their normal and random distribution, which confirms the parity of the sample members.

Tools and devices used in the research

The researcher used a variety of methods to collect data in a manner appropriate to the nature of the research.

\section{A- Classification of tools and means of data collection}

The researcher classified the tools and means of data collection in the research into the following:

\section{The tools used in the research}

- Registration form for the results of the measurements

- Syringes $5 \mathrm{~cm}$.

Medical swabs for sterilization before prickling

Edita anticoagulant tubes for blood analysis (lactic acid)

- Tubes with Florid fluoride to analyze lactic acid

- Kits to detect lactic acid in the blood

\section{The devices used in the research}

- A medical scale calibrated to measure the weight of the nearest kilogram.

- A tape measure to measure length and distance in some tests

- 2 hours off time, to determine the time in some tests.

\section{Biochemical measurements}


- The percentage of lactic acid.

- The maximum oxygen consumption

\section{Forms and personal interviews}

The researcher undertook the study and reference survey of Arab and foreign scientific references and previous studies specialized in the field of sports training in general and triathlon training in particular with the aim of identifying and defining the most important and most appropriate tests needed to measure physiological variables. The researcher designed the following:

- A questionnaire for the opinion of experts who have passed 8-10 years of experience, each of:

- The tests under study (physiological).

The appropriateness of stretching exercises using the neuromuscular facilitation method for sensory receptors used as well as repetitions, number of groups and appropriate rest period in addition to the intensity of the exercises under consideration

Time distribution of the program and the training units.

- A data collection form to record each player's data.

\section{Fifth: Administrative procedures}

The researcher has carried out the following administrative procedures to facilitate the conduct of research measurements: -

1- Obtaining the approval of the Badr Park Club administration, after meeting all administrative requirements, to obtain:

Facilities to provide the number of sample individuals Approval of applying the program in the swimming pool and the club's private field

Facilitating the ability to draw blood samples for players

Allow the measurement of weight and height

2- Ensuring the sample's desire to participate in the program and adhering to the program's implementation dates, by informing the player's guardian of a form to understand the importance and objectives of the research and the procedures followed for applying to the research sample, and signing the form by the guardian in the event that the player's participation in the program .

3- Agreeing on the time for making the required measurements for the research sample and determining the dates for implementing the program, to be in the morning (Saturday, Monday and Wednesday)

4- Seek the opinions of the experts in physical education in the field of training 'trainers with experience in the field of triathlon to develop the training program, through a survey of the opinion of experts.

\section{Scientific coefficients for the tests used in the research}

The scientific treatments for the tests used were performed on the reconnaissance sample as follows:

\section{A- Honesty:}


To calculate the honesty, the researcher calculated the concomitant honesty by surveying the experts' opinion on the physiological tests under consideration.

Table (4)

The percentage of expert opinions on all variables tests in question to calculate honesty

$(\mathrm{N}=10)$

\begin{tabular}{|c|c|c|c|c|}
\hline \multicolumn{2}{|c|}{ Variables } & measruing unit & Repetition & $\%$ \\
\hline \multicolumn{2}{|c|}{ Age } & Year & 10 & $100 \%$ \\
\hline \multicolumn{2}{|c|}{ Length } & $\mathrm{Cm}$ & 10 & $100 \%$ \\
\hline \multicolumn{2}{|c|}{ the weight } & Kg & 10 & $100 \%$ \\
\hline \multicolumn{2}{|c|}{ Training age } & Year & 10 & $100 \%$ \\
\hline \multirow{2}{*}{$\begin{array}{c}\text { Lactic } \\
\text { acid }\end{array}$} & Lactic acid & Micromol / L & 10 & $100 \%$ \\
\hline & Vo2 max & meter & 10 & $100 \%$ \\
\hline
\end{tabular}

Table (4) shows the experts' approval (100\%) in all the variables tests under consideration, which indicates the truth.

\section{B- Persistence}

The researcher used the method of applying the test and re-applying it (Test- Re test), so she conducted the first application of the tests on the 6-man poll sample on Monday 15/4/2019, then re-applying the tests for the second time on the same sample in On Monday 29/4/2019 with a difference of two weeks between the first application and the second application as follows: -

Table (5)

Correlation coefficient between the first and second measures For the exploratory sample in all variables under consideration to calculate stability( $N=6)$

\begin{tabular}{c|c|c|c|c|c|c|c}
\hline & & \multicolumn{2}{|c|}{ The first measurement } & \multicolumn{2}{|c|}{ The second measurement } & & \multirow{2}{*}{ P } \\
\cline { 3 - 8 } Variables & $\begin{array}{c}\text { measruin } \\
\text { g unit }\end{array}$ & $S$ & $\bar{X}$ & $S$ & $\bar{X}$ & $\mathrm{R}$ & $\begin{array}{c}\mathrm{P} \\
\text { (Value) }\end{array}$ \\
\hline \hline Age & Year & 1.17 & 13.83 & - & - & - & - \\
\hline Length & $\mathrm{Cm}$ & 4.62 & 159.17 & - & - & - & - \\
\hline the weight & $\mathrm{Kg}$ & 3.69 & 53.00 & - & - & - & - \\
\hline
\end{tabular}




\begin{tabular}{c|c|c|c|c|c|c|c}
\hline Training age & Year & 0.55 & 2.50 & - & - & - & - \\
\hline Lactic acid & $\begin{array}{c}\text { Micromol / } \\
\mathrm{L}\end{array}$ & 368.78 & 1400.00 & 368.78 & 1400.01 & $\mathbf{0 . 9 9 *}$ & 0.00 \\
\hline \hline
\end{tabular}

* Indication at the value of $(p)>(0.05)$.

Table (5) shows the presence of a statistically significant correlation coefficient in the values of all the tests of the variables under investigation, which indicates its stability.

\section{Research program design}

The researcher designed the proposed training program, where the training program is considered one of the most important requirements that trainers undertake, and without them the level of players is not elevated and therefore the training program must be built for the individual response and therefore must take into account the different capabilities of the player as well as his functional response in order to put the severity and size as well as comfort Suitable for player abilities.

\section{The researcher designed the research program based on:}

\section{Scientific references and related studies}

The researcher conducted a survey of scientific references and special research related to the subject of research and the use of the international information network

\section{- Opinion poll}

After a survey of experts in the field of physical education and triathlon training to determine the appropriate period for the application of the program, the duration of the program implementation, the number of weekly training units, the time of the t12raining unit and the time of conducting the training unit, it was presented to (10) experts. The results of the presentation resulted in the implementation of the program during the special preparation period And precompetitions.

\section{Table (6)}

The time distribution of the training units

\begin{tabular}{c|c|c|c}
\hline \hline $\begin{array}{c}\text { The number of } \\
\text { weeks }\end{array}$ & $\begin{array}{c}\text { The number of } \\
\text { weekly units }\end{array}$ & $\begin{array}{c}\text { The total number of } \\
\text { units }\end{array}$ & $\begin{array}{c}\text { The time of application } \\
\text { of the training unit }\end{array}$ \\
\hline 12 & 3 & 36 & $90 \mathrm{~m}$ \\
\hline \hline
\end{tabular}




\section{1- Determine the objectives of the proposed training program}

- Development of some physiological variables of the sample in question

- Improve the systolic amplitude of the working muscles and the muscle group on the moving parts according to their functional description.

\section{2- Defining the contents of the proposed training program}

The proposed training program contains a set of exercises and distances of high intensity until the performance level of the sample is developed, so the program includes the special preparation stage and pre-competitions and skillful exercises for free swimming varied with high intensity, so that the body can adapt to work with the rate of lactic acid accumulation and the application began in the special preparation stage From the training season.

3- The foundations that were taken into consideration when developing the proposed training program.

- -Flexibility of the training program and its acceptance of scientific application.

- The content of the training program is appropriate to the research sample.

- The possibility of providing the tools used in the training program.

- Pregnancy degrees in terms of severity, size and density are appropriate for the research sample.

- Gradient from easy to difficult, from simple to complex.

4- The conditions (foundations) that were taken into account when carrying out the exercises within the training program, taking into account the following:

- Objective of the program.

- Continuity in implementing the program.

- Achieving the principle of individual differences and the training status of each young person.

- Gradient from easy to difficult, from simple to complex.

- Consider diversification in choosing exercises to avoid feeling bored.

- Determining the appropriate loads according to the level of the youth.

- Taking into account the physiological characteristics of the dental stage of the individuals in the sample in question. 
- Taking into account rest periods between exercise and the other, and between training units and some of them, so that recovery can be restored.

- Achieve security and safety factors during the application of the program.

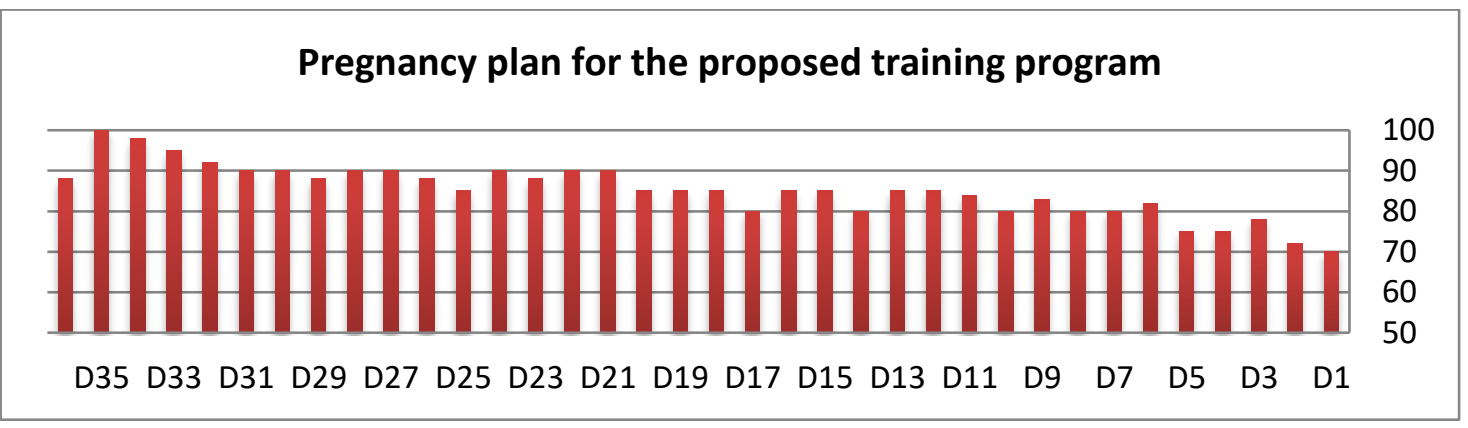

Figure. (1)

\section{Executive steps of the research:}

After defining the community and sample of the research, and interviewing some of the expert experts in the sport of triathlon and specialists in the field of sports training in order to get acquainted with the dimensions of the training program and the contents of the proposed program, the researcher did the following: -

\section{Exploratory experience}

- The exploratory experiment was conducted on Monday 15/4/2019 to $4 / 29 / 2019$ on a sample outside the research sample and consisted of (6) players in order to discover what negatives can be addressed before starting the basic study, to know the following points:

- Determine where to apply the program.

- Ensure that the proposed program is suitable for the research sample.

- Discover the difficulties facing the implementation of the program units.

- Providing the devices and tools necessary for the study.

- Determine the validity of the devices and tools used.

- Checking the helpers and taking the data in a correct, organized and fast manner.

\section{Tribal measurements}

- The tribal measurements were made for all individuals of the sample in question in each of the following measurements:

- Measuring variables (age - height - weight - training age), explaining the training program and its goal on Saturday 6/8/2019

- Measurement of physiological variables (lactic acid and maximum oxygen consumption) on Wednesday 12/6/2019

\section{Program implementation}


The proposed training program was implemented for the individuals in the sample from 15/6/2019 to 18/9/2019 for a period of 12 weeks (three months) at the rate of 3 weekly training units at 36 training units during which they made a follow-up phase measurements to codify the training load and amendment if Necessary.

\section{Dimensional measurements}

Lactic acid (by analyzing the blood three minutes after performance) and the maximum oxygen consumption (through the Cooper test) were measured on Monday $9 / 21 / 2019$ under investigation by individuals in the sample.

\section{Statistical treatments used in the research}

The researcher used SPSS program to calculate the following statistical treatments: -

- Arithmetic mean (X)

- Standard deviation (s)

- $\quad$ Torsional coefficient $\left(\propto \_3\right)$

- Normal distribution test Kolmogorov-Smirnov (Z)

- Runs Test (Z)

- Difference t - test

- Correlation coefficient (r)

- Improvement ratios

\section{View and discuss the results}

In light of the research objectives, the researcher presents the results: -

Table (7)

An indication of the differences between pre and post measurements in the physiological variable (lactic acid) $(\mathrm{N}=11)$

In the blood after exertion - the maximum oxygen consumption)

\begin{tabular}{|c|c|c|c|c|c|c|c|c|c|}
\hline \multirow{2}{*}{ Variables } & \multirow{2}{*}{$\begin{array}{c}\text { measruing } \\
\text { unit }\end{array}$} & \multicolumn{2}{|c|}{$\begin{array}{l}\text { Tribal } \\
\text { measurement }\end{array}$} & \multicolumn{2}{|c|}{$\begin{array}{l}\text { Dimensional } \\
\text { measurement }\end{array}$} & \multirow[t]{2}{*}{$\begin{array}{l}\text { differ } \\
\text { ence }\end{array}$} & \multirow[t]{2}{*}{$\mathrm{t}$} & \multirow{2}{*}{$\begin{array}{l}\text { P } \\
(\text { val } \\
\text { ve })\end{array}$} & \multirow{2}{*}{$\begin{array}{l}\text { Impr } \\
\text { ovem } \\
\text { ent } \\
\text { rate }\end{array}$} \\
\hline & & $\bar{X}$ & $\boldsymbol{S}$ & $\overline{\boldsymbol{X}}$ & $\boldsymbol{S}$ & & & & \\
\hline Lactic acid & $\begin{array}{c}\text { Micromol / } \\
\text { L }\end{array}$ & 1.12 & 0.18 & 0.96 & 0.13 & 1.12 & $3.68^{*}$ & 0.00 & $117 \%$ \\
\hline $\begin{array}{c}\text { Maximum } \\
\text { oxygen } \\
\text { consumption }\end{array}$ & meter & 1522.73 & 348.83 & 1800 & 340.59 & 277.27 & $\overline{7.34} *$ & 0.00 & $18 \%$ \\
\hline
\end{tabular}

* Indication at the value of $(\mathrm{p})>(0.05)$. 
It is clear from Table (7) that there are statistically significant differences between the pre and post measurements in the physiological variable (lactic acid in the blood after the effort - the maximum oxygen consumption).

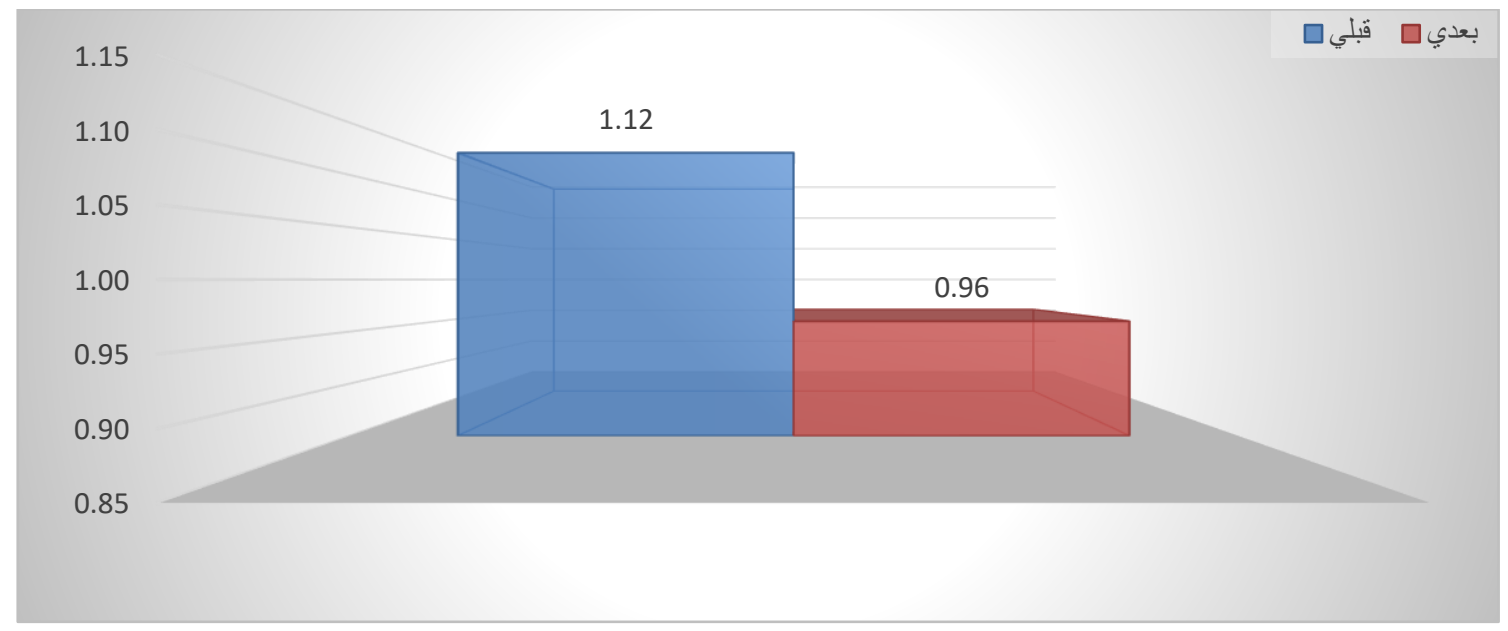

Figure ( 2 )

Arithmetic mean of the tribal and dimensional measurements of lactic acid

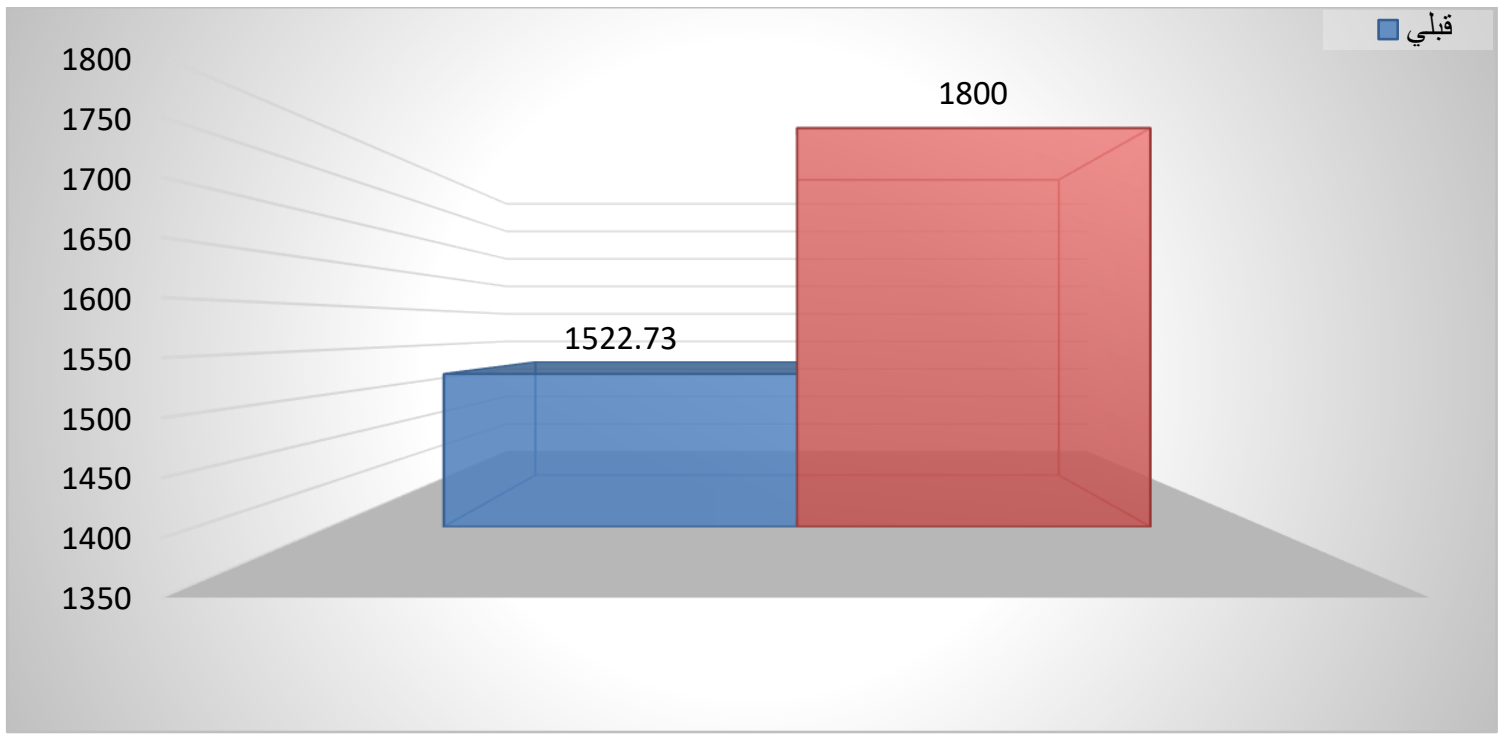

Figure ( 3 )

The arithmetic mean of the tribal and dimensional measurements of the maximum oxygen consumption

\section{Discuss the results}

The hypothesis states that "there are statistically significant differences between the pre and post measurements in favor of the post measurement in the physiological variables represented in (the level of lactic acid in the blood after performance - the maximum oxygen consumption)"

It is clear from Table (7) and Figure (2) and (3) that there are statistically significant differences between the pre and post measurements in the 
physiological variable (lactic acid in the blood after exertion - the maximum oxygen consumption).

The researcher attributed the improvement of the level of lactic acid after the performance to the improvement of the circulatory system and the increase in the body's efficiency and the ability to perform with the presence of lactic acid and consequently the delay in the appearance of fatigue which led to an increase in the ability of the players to withstand physical performance in the presence of lactic acid, as the researcher returns the improvement of the maximum oxygen consumption To improve the circulatory system and improve the body's ability to absorb the largest amount of oxygen

"Abu El-Ela Abdel-Fattah" and "Brent Rushall" indicate an increase in lactic acid that causes its disability in the muscle contractions and causes the pain felt by the player. (1: 168)

And the association of lactic in the blood is associated with strong performance and period of vortex, as well as the rate of maximum consumption of oxygen, and when the concentration of lactic in the blood is about $5.5 \mathrm{mmol} /$ minute, it is an indication of the improvement of lactic production and reduction of disposal operations, while $2.5 \mathrm{mmol} /$ minute is indicative of an improvement in Operations to get rid of it as well as increase the rate of oxygen consumption, and the production and disposal of lactic is an individual process for each player and is a means to predict the ability to withstand performance. (5: 174)

The researcher agreed with Chao-Chung (2005) (7), Sawka et al. (2004) (11) and Israa Fouad Saleh (2004) (4) until a decrease The concentration of lactic acid in the blood indicates an improvement in the functional status of the players, and their ability to continue in physical performance so that the player maintains his speed along the race distance, which proves that the training led to the development of the special endurance characteristic, which is one of the most important basic elements. (11: 156) (4: 99)

The researcher believes that the adoption of the training program on the diversity between moving and fixed muscle contraction, which allows the muscle tissue to adapt to the nature of any muscle work performed and leads to a decrease in the concentration of lactic acid and increase the ability of the muscle to carry, which leads to the development of performance.

Thus, the third hypothesis is partially validated, which states that "there are statistically significant differences between the pre and post measurements in favor of the post measurement in the physiological variables represented in (the level of lactic acid in the blood after performance - the maximum oxygen consumption)" 


\section{Conclusions}

In the light of the research problem and the goals and within the limits of the research sample, what indicates the results of this study and according to the results of the statistical treatment, the following conclusions were reached:

- The proposed program using some methods of neuromuscular facilities for sensory receptors had a positive effect on the physiological level of the triathlon player.

\section{Recommendations}

Through the results of the research and in light of the researcher's findings, the researcher recommends the following: -

1- Applying the proposed program with the help of research methods that depend on the neuromuscular facilities used in this study on sports teams similar to the research sample because of its positives in advancing the skill, physical and physiological level of the triathlon players.

2- Attention must be paid to taking into account the individual differences between the players when training in the methods that use the sensory receptors (PNF) work on different skills until improvement occurs in an integrated way for all players while avoiding injuries.

3- Paying attention to the periodic system measurements along with physical measurements to get to know the competence of players during training periods

4- Use relaxation and calming exercises during the rest, which helps to get rid of lactic acid in the blood.

5- Applying exercises using the neuromuscular facilitation method at other dental stages

6- Supporting sports facilities with medical analysis laboratories or medical devices, through which they benefit in monitoring, evaluating and developing training programs through the concentration of lactic in the blood. 


\section{List of references}

First: Arabic references:

1. Abu Al-Ella Ahmed Abdel-Fattah, Brent Rashal 2016: Swimming Training Methods, USRPT Training, Very Short Speed Regulation, Modern Book Center, Cairo.

2. Abu El-Ela Abdel-Fattah, Hazem Hussein Salem 2011: Contemporary Trends in Swimming Training, Dar Al-Fikr Al-Arabi, Cairo.

3. Ahmed Nasr El-Din Al-Sayed 2019: Principles of Physiology of Sport, Modern Book Center, 2nd edition, Cairo

4. Israa Fouad Saleh, 2004: Determining the most appropriate rest period according to the pulse rate for repetitive training and its effect on special speed tolerance and concentration of lactic acid in the blood. Achievement of running 800 meters. Unpublished PhD thesis, University of Baghdad, College of Sports Education.

5. Abdel Rahman Zaher 2011: Encyclopedia of Sport Physiology, Cairo Book Publishing Center.

6. Mohamed Mahmoud Abdel-Zahir 2017: Physiology of Fatigue and Sports Hospitalization, Modern Book Center, Cairo

\section{Second: Foreign references:}

7. Chao-Chung Lee, Ray-Yau Wang, Yea-Ru Yang, 2005 :Effects of Proprioceptive Neuromuscular Facilitation on Balance \& Mobility Performance of individuals with chronic stroke" A preliminary report, Institute of Physical Therapy, National Yang-Ming University, Taipei, Taiwan.

8. International Training Unit 2019: KTF -ITU level (1) coaches course ، Korea.

9. Kathy Stevens 2007 : A theoretical overview of stretching and flexibility, American Fitness, printed from find articles .COM, located

10. Michael Alter, MS , 2014 : " Science of Flexibility " , $2^{\text {nd }}$, Edition human kinetrce

11. Sawka, M., Knowlion,R., \& Miles, P., 2004 : Competition Blood lactate concentration in collegiate swimmers Eur., Journal of Appl.

Physiology, Vol

12. triathlon Canada 2006 : triathlon competition introduction, coaching course manual . Toronto, on triathlon Canada. 
13. Vivian H. Heyward 2010 : Advanced Fitness Assessment \& Exercise prescription, 3 ed - Human Kinetics - USA Wobert . Mcatee

Third: International information network site

14. http://www.triathlon .org 